\title{
Vaccination Coverage and Its Determinants in Children Aged 11 - 23 Months in an Urban District of Nigeria
}

\author{
Beckie Nnenna Tagbo1,2, Christopher Bismarck Eke ${ }^{2,3}$, Babatunde Ishola Omotowo4, \\ Chika Nwanma Onwuasigwe ${ }^{4}$, Edelu Benedict Onyeka ${ }^{2,3}$, Ukoha Oluchi Mildred2 \\ ${ }^{1}$ Institute of Child Health, University of Nigeria Teaching Hospital, Ituku-Ozalla, Nigeria \\ ${ }^{2}$ Department of Paediatrics, University of Nigeria Teaching Hospital, Ituku-Ozalla, Nigeria \\ ${ }^{3}$ Department of Paediatrics, College of Medicine University of Nigeria, Ituku-Ozalla, Nigeria \\ ${ }^{4}$ Department of Community Medicine, University of Nigeria Teaching Hospital, Ituku-Ozalla, Nigeria \\ Email: chriseke2006@yahoo.com
}

Received 22 August 2014; revised 22 September 2014; accepted 21 October 2014

Academic Editor: Praveen Kumar Amancha, Emory University, USA

Copyright (C) 2014 by authors and Scientific Research Publishing Inc.

This work is licensed under the Creative Commons Attribution International License (CC BY).

http://creativecommons.org/licenses/by/4.0/

(c) (i) Open Access

\section{Abstract}

Background/Objectives: Performance of the vaccination programme in Nigeria is lower than the regional average as well the $95 \%$ target necessary for sustained control of vaccine preventable diseases. This study is aimed at assessing the vaccination coverage and its associated factors in children aged 11 - 23 months in Enugu Metropolis. Methods: A cross sectional study in which caregivers and their children pair, aged $11-23$ months attending children's outpatient clinics in Enugu metropolis was undertaken. Respondents were selected consecutively while data were collected using pretested interviewer administered semi-structured questionnaire. Data were analyzed using SPSS version 20.0 while level of significance was set at $p<0.05$. Logistic regression analysis was used to identify independent predictors of full vaccination. Results: Of 351 subjects studied, $84.9 \%$ (298) were fully immunized according to the national programme on immunization schedule using both vaccination cards and history. The OPV0, OPV3, pentavalent-1, pentavalent- 3 and measles coverage at the time of survey were $100.0 \%, 97.2 \%, 98.0 \%, 98.6 \%, 96.9 \%$ and 95.4\%, respectively. On logistic regression: maternal occupation (government employees), children born in government hospitals and knowledge of when to start and complete vaccinations in a child were the likely predictors for completion of full vaccination in the children. Conclusion: The vaccination coverage among the study group was adjudged to be relatively high. Delivery of a child in a government hospital and the knowledge of the age when routine vaccinations should begin

\footnotetext{
${ }^{*}$ Corresponding author.
}

How to cite this paper: Tagbo, B.N., Eke, C.B., Omotowo, B.I., Onwuasigwe, C.N., Onyeka, E.B. and Mildred, U.O. (2014) Vaccination Coverage and Its Determinants in Children Aged 11 - 23 Months in an Urban District of Nigeria. World Journal of Vaccines, 4, 175-183. http://dx.doi.org/10.4236/wjv.2014.44020 
and end in a child were the independent predictors of the high vaccination coverage rate observed. Awareness and health education efforts in government tertiary hospitals should be extended to private and other hospitals to improve and sustain national vaccination coverage in Nigeria.

\author{
Keywords
}

Vaccination, Immunization, Coverage, Children, Nigeria

\title{
1. Introduction
}

The expanded programme on immunization (EPI) was established in 1974 by the World Health Organization (WHO) with the mandate of ensuring full accessibility of the routine vaccines by all children. However, in spite of all the improvements in global coverage of routine vaccinations in children especially Diphtheria-PertussisTetanus Toxoid (DPT3) containing vaccine - third dose (which is a key indicator of immunization programme performance) coverage from 5\% in 1974 to $83 \%$ in 2011 globally, almost one-fifth of the world's children had not received the DPT3 series during their first year of life [1]. Most of these unvaccinated children live in developing countries [2], particularly Nigeria with a teeming population of about 167 million people [3], and an annual population growth rate of $2.7 \%$ [4]. Receipt of vaccines at the recommended ages and intervals will ensure that children are adequately protected from target diseases at all time [5]. This will help to fast-track achievement of the Millennium Development Goals.

Vaccine preventable diseases (VPDs) have been reported to account for $17 \%$ of global under five mortality per annum [6], while in Nigeria $27 \%$ of child mortality amounting to over 200,000 deaths per year have been attributable to VPDs [7]. It is of interest to note that the Nigeria's under five mortality rate is 124 per 1000 and currently ranking 9th according to recent United Nations Children's Fund (UNICEF) estimates [4]. Additionally, recent Nigeria Demographic and Health Survey (NDHS) 2009 estimated that the proportion of children were fully immunized to be $23 \%$ by age of 23 months, with broad geographic variations in estimates. Similarly, current national estimates revealed DPT3 average of $71 \%$ and oral polio vaccine third dose (OPV3) coverage of $62 \%$ with lower coverage noted across the northern states [8].

In spite of the narrow range of antigens currently available to the average Nigerian child from the government schedule (including BCG, OPV, pentavalent vaccine, hepatitis B vaccine, yellow fever and measles), routine vaccination coverage still remained very low [9]. Also, numerous programmes and strategies specifically designed by the government and development partners have also failed to improve the vaccination coverage in some parts of the country. Nigeria is one of the polio endemic countries with Pakistan and Afghanistan (PAN) and one of the eleven countries accounting for $66 \%$ of the world's measles mortality [10]. It has been advanced that, until polio transmission is interrupted in these countries including Nigeria; all countries remain at risk of polio transmission [10].

Several factors have been implicated as possible mitigating factors of low vaccination coverage in developing/low income countries including Nigeria. These factors include lack of political will, poor work attitude and malorientation of health workers, poor health infrastructure, religious insurgency/terrorism, ignorance, cultural/ religious average aversion to vaccine acceptance or use, misconceptions about safety of the vaccines and lack of awareness about availability of vaccination services, inadequate cold chain facilities and vaccine stock-outs among others [8]-[16].

Hence this study is aimed at assessing the vaccination coverage and its determinant factors in children aged 11 - 23 months in Enugu metropolis.

\section{Methods}

\subsection{Study Location}

This study was conducted in Enugu Urban, the capital city of Enugu State, southeast Nigeria.

Enugu urban is made up of 3 local government areas namely: Enugu East, Enugu North and Enugu South. Enugu metropolis has a population of 722,664 according to 2006 national census figures [17]. 


\subsection{Study Duration}

Study was carried out over a two month period (6th January-5th March, 2014).

\subsection{Study Design}

This is a cross sectional descriptive study involving mothers/caregivers and their children pair aged 11 - 23 months attending four major public children's outpatient clinic in Enugu metropolis including University of Nigeria Teaching Hospital (UNTH), Enugu; Enugu State University of Science and Technology Teaching Hospital, Park Lane Enugu, Poly-Clinic Asata, Enugu, and Nike Cottage Hospital. The respondents were selected consecutively upon their informed consent.

Information sought included socio demographic variables of the mothers/caregivers and their respective children pair, vaccination coverage levels of the various antigens administered to children, different levels of knowledge and attitude regarding vaccination among the children as well as perceived barriers to vaccination in the study locale. Data were collected using pretested interviewer administered semi-structured questionnaire.

\subsection{Ethical Considerations}

Ethical approval for the study was sought from the Health Research Ethics Committee of UNTH, Enugu prior to the commencement of the study while informed written consent was obtained from the selected interviewees prior to their participation in the study.

Data analysis was done using SPSS version 20.0 and presented in frequencies while chi-square was used to test association between dependent and independent variables. Binary logistic regression analysis was done for those independent variables that were statistically significant for full immunization coverage among children aged 11 - 23 months old. The level of significance was set as $\mathrm{p}<0.05$.

\subsection{Definitions Applied in the Study}

Fully vaccinated: any child who had received a dose each of BCG, hepatitis B, measles and yellow fever vaccines as well as four doses of oral polio vaccine and 3 doses of pentavalent vaccine respectively.

Unvaccinated: any child who is yet to receive any of the above 11 doses.

Partially vaccinated: any child who has received one or more but less than the 11 doses.

Coverage by card only: coverage determined on documented vaccine and dose without those vaccinated by oral history.

Coverage by card plus history: coverage assessed based on documented vaccines on the card and caregivers (recall) history.

\section{Results}

A total of 351 respondents were enrolled and studied out of which 183 (53.6\%) were female while 163 (46.4\%) were males giving a male to female ratio of $1: 1.16$.

Majority of the interviewees (144; 41.3\%) were aged between 26 and 30 years. Those who had attained at least primary education were fewer, 29 (8.3\%) compared to those with secondary, 157 (44.7\%). Majority of the enrolled children in the study were aged 12 - 15 months, 164 (46.7\%) while those aged 16 - 20 months constituted 127 (36.2\%). Nearly all the respondents were of Christian religious background (343; 97.7\%). See Table 1.

The current study showed that majority of the children, 298 (84.9\%) were fully vaccinated by card and caregivers oral report. There was a statistically significant difference $(p=0.008)$ between the proportions of fully immunized children delivered at different types of health facility. While $100 \%$, 89\% and $84 \%$ of children delivered at health centres, teaching/specialist hospitals and private hospitals respectively, were fully immunized; only $77 \%$ of children delivered at Maternity homes were fully immunized.

Of the total respondents, 335 (95.4\%) had heard about vaccination. 315 (89.7\%) of the interviewees, correctly knew that the main objective of vaccinating a child was to prevent specific diseases. 335 (95.4\%) reported that they knew about vaccinations mainly from hospital health education usually when they visited the hospital either for antenatal or other child health clinics. 
Table 1. Demographic characteristics of the children and their mothers.

\begin{tabular}{|c|c|c|}
\hline Demographic characteristic & Frequency $(\mathrm{N}=351)$ & Percent (\%) \\
\hline \multicolumn{3}{|l|}{ Sex of the children: } \\
\hline Female & 188 & 53.6 \\
\hline Male & 163 & 46.4 \\
\hline \multicolumn{3}{|l|}{ Age group (months) of children: } \\
\hline $10-15$ & 164 & 46.7 \\
\hline$>15-20$ & 127 & 36.2 \\
\hline$>20-25$ & 60 & 17.1 \\
\hline \multicolumn{3}{|l|}{ Age group (years) of mothers: } \\
\hline$\leq 20$ & 21 & 6 \\
\hline$>20-25$ & 56 & 16 \\
\hline$>25-30$ & 144 & 41.3 \\
\hline$>30-35$ & 69 & 19.7 \\
\hline$>35-40$ & 43 & 12.3 \\
\hline$>40$ & 16 & 4.6 \\
\hline \multicolumn{3}{|l|}{ Religion: } \\
\hline Christianity: & 343 & 97.7 \\
\hline Islam & 8 & 2.3 \\
\hline \multicolumn{3}{|l|}{ Mother's occupation: } \\
\hline Government employee & 84 & 23.9 \\
\hline Private employee & 41 & 11.7 \\
\hline Self employed & 93 & 26.5 \\
\hline Trader & 82 & 23.4 \\
\hline Housewife & 51 & 14.5 \\
\hline \multicolumn{3}{|l|}{ Mother's educational status: } \\
\hline No formal education & 6 & 1.7 \\
\hline Primary & 29 & 8.3 \\
\hline Secondary & 157 & 44.7 \\
\hline Tertiary & 159 & 45.3 \\
\hline
\end{tabular}

Among the children surveyed, their vaccination cards were sighted and confirmed in 149 (42.5\%) of them while $84.9 \%$ completed all the vaccinations (by card and recall).

Knowledge about VPDs was highest for polio, 284 (80.9\%), followed by measles 74.1\% while H. influenza type b was the least, 60 (17.1\%) as shown in Table 2.

Respondents' knowledge about the various vaccines obtainable in the national immunization programme (NPI) was highest for measles 272 (77.5\%), followed by OPV, 259 (73.8\%) while knowledge for pentavalent and hepatitis B trailed behind with 110 (49.0\%) and 150 (42.7\%) respectively (Table 3).

A significant proportion of the interviewees $308(87.7 \%)$ who were fully vaccinated correctly reported that Nigeria's routine vaccinations should start at birth $\left(x^{2}=10.568 ; p=0.014\right)$ and be completed at 9 months $\left(x^{2}=\right.$ 15.449; $\mathrm{p}=0.001$ ) respectively.

One hundred and ninety four (55.3\%) of the interviewees reported that a sick child should not be immunized. Only 9 (2.6\%) of the study children were not vaccinated and the various reasons given by their mothers/caregivers included: no health facilities 2 (22.2\%), religions reasons 2 (22.2\%), health workers not available 
Table 2. Knowledge of vaccine preventable diseases (VPDs).

\begin{tabular}{ccc}
\hline VPDs & $(\mathrm{N}=351)$ & $\%$ \\
\hline Polio & 284 & 80.9 \\
Measles & 260 & 74.1 \\
Yellow fever & 215 & 61.3 \\
Tuberculosis & 210 & 59.8 \\
Tetanus & 162 & 46.2 \\
Hepatitis B & 129 & 36.8 \\
Pertussis & 109 & 31.1 \\
Diphtheria & 99 & 28.2 \\
H. influenza & 60 & 17.1 \\
\hline
\end{tabular}

Table 3. Knowledge of vaccines in the national routine immunization schedule.

\begin{tabular}{ccc}
\hline Vaccine & Know $^{*}$ that the vaccine is in the national $\mathrm{RI}^{+}$schedule \\
\hline BCG & $(\mathrm{N}=351)$ & $\%$ \\
Hepatitis B & 245 & 69.8 \\
Oral polio & 150 & 42.7 \\
Vaccine & 259 & 73.8 \\
Pentavalent/H. flu & 172 & 49.0 \\
Measles & 272 & 77.5 \\
Yellow fever & 199 & 56.7 \\
\hline
\end{tabular}

*Knowledge; ${ }^{+}$Routine immunization.

$1(11.1 \%)$, vaccination is of no benefit 1 (11.1\%), cultural reasons $1(11.1 \%)$, fear of side effects $1(11.1 \%)$ and did not know 1 (11.1\%).

Reasons for default from completing immunization among the caregivers studied included: health workers are not always available, ignorance, busy schedule, did not know about another dose, child sick, caregiver sick, Vaccination time is inconvenient, and mother/caregiver is busy.

The drop-out rates are as follows: pentavelent 1 -pentavalent 3 (DPT containing) vaccine $-0.0002 \%$ while BCG-measles drop-out rate- $4.6 \%$. The various immunization coverage for all the vaccines contained in the national routine immunization programme were as shown in Table 4.

Predictors of full vaccination coverage in the current study following subjection of all independent variables identified to be significantly associated with vaccination coverage to regression analysis are as shown in Table 5.

Children of mothers that knew that a child should start immunization at birth are 1.9 times more likely to be fully immunized, while children of those that knew that a child should complete immunization at age of one year are 0.34 less likely to be fully immunized. Children of mothers that had secondary and tertiary education are 2 times more likely to be fully immunized than those children whose mothers had primary or no formal education. Also, children of mothers that were employed by government were 2.3 times more likely to be fully immunized than those that are not working with the government.

Children that were delivered in health facility are about 1.1 times more likely to be fully immunized than those that were delivered at home and by TBAs. Also, those that can reach health facility in less than one hour are 1.6 times more likely to be fully immunized. These variables were statistically significant before logistic regression analysis was done. 
Table 4. Vaccination coverage $(\mathrm{N}=351)$.

\begin{tabular}{ccc}
\hline Vaccines & N & $\%$ \\
BCG & 351 & 100.0 \\
OPV0 & 351 & 100.0 \\
Hep B & 344 & 98.0 \\
OPV1 & 341 & 97.2 \\
Penta 1 & 346 & 98.6 \\
OPV 2 & 344 & 98.0 \\
Penta 2 & 345 & 98.3 \\
OPV3 & 341 & 97.2 \\
Penta 3 & 340 & 96.9 \\
Measles & 335 & 95.4 \\
Yellow fever & 340 & 96.9 \\
\hline
\end{tabular}

Table 5. Logistic regression of child fully immunized and knowledge on when a child should start and complete immunization, mothers education and occupation.

\begin{tabular}{|c|c|c|c|c|c|}
\hline \multirow{2}{*}{ Variable: } & \multirow{2}{*}{$\beta$} & \multirow{2}{*}{ Sig } & \multirow{2}{*}{$\operatorname{Exp}(\beta)$} & \multicolumn{2}{|c|}{ 95.0\% C.I. for $\operatorname{Exp}(\beta)$} \\
\hline & & & & Lower & Upper \\
\hline Age a child should start immunization & 0.648 & 0.147 & 1.92 & 0.796 & 4.592 \\
\hline Age a child should complete immunization & -1.066 & 0.001 & 0.344 & 0.185 & 0.640 \\
\hline Mothers education & 0.701 & 0.124 & 2.017 & 0.824 & 4.934 \\
\hline Mothers occupation & 0.837 & 0.043 & 2.309 & 0.925 & 5.764 \\
\hline Facility where delivery took place & 0.046 & 0.691 & 1.047 & 0.835 & 1.312 \\
\hline
\end{tabular}

$\beta=$ standardized coefficient; $\operatorname{Sig}=\operatorname{significance} ; \operatorname{Exp}(\beta)=\operatorname{exponent}$ of $\beta$; C.I. for $\operatorname{Exp}(\beta)=$ confidence interval for exponent of $\beta$.

\section{Discussion}

The vaccination coverage of $84.9 \%$ observed in the present study is high. It compares favorably well with the global average rate of $83 \%$ reported in 2011 , although it is lower than the $95 \%$ vaccination coverage target which is necessary for the sustained control of vaccine preventable diseases [18].

Also, the rate observed in this urban centre in south eastern Nigeria is higher than a previous vaccination coverage reported among Nigerian [19] and Malawian [20] populations.

The pentavalent 3 (DPT containing) vaccine coverage rate in our study was $98.3 \%$ which is very high and seems to be higher than that reported in Nigeria studies and other African countries [21]-[24]. DPT3 coverage is key to adequate vaccination coverage in children. The high pentavalent 3 vaccine coverage could partly be due to emerging urbanization with better access to social amenities including health infrastructure/services, mothers/ caregivers knowledge about vaccination services and high sensitization and motivation of the population studied.

Also there is high concentration of health facilities in Enugu urban city including two teaching hospitals (University of Nigeria Teaching Hospital, Enugu and Enugu State University of Science and Technology Teaching Hospital Park Lane, Enugu), some private specialist hospitals and government owned immunization centres) as well as high mobilization for routine immunization and supplemental national immunization days by the health workers. The finding of higher proportions of fully vaccinated children among those delivered in primary and tertiary health care facilities compared to Maternity homes underscores the importance of health education as well as training and re-training of healthcare personnel. There is need to integrate health workers in 
Maternity homes into the national and state training programmes as well as vaccination activities.

Assessment of care-givers knowledge on vaccination and vaccine preventable diseases showed very high rates as previously reported by Tagbo et al. [14] and this could account for the high level of vaccination coverage rates observed in the current study.

However, care-givers knowledge for Haemophilus influenza type b and hepatitis B vaccination were low compared to other vaccines. This could be as a result the fact that the hepatitis B and Haemophilus influenza type $b$ vaccines were recently introduced into the national programme on immunization (NPI) in our setting [9].

It was observed that children born in hospital particularly teaching/specialist hospital were more likely to complete their vaccinations. This could be influenced by the fact that most of the babies received their first doses of vaccinations before discharge following their deliveries in the hospital as well as the fact that caregivers received adequate health education regarding child hood vaccinations. Such findings have been corroborated by other workers [12] [24].

Besides the relationship of vaccination coverage with place of delivery of the child, complete vaccination coverage of the children in the current study could likely be as a result of the high knowledge of vaccination 335 (95.4\%) and VPDs 315 (89.7\%) among the respondents (care-givers). Majority of the respondents reported that they learnt about vaccinations from health care staff and this agrees with findings in similar studies in Ethiopia [12], and Nigeria [25].

Knowledge of the age at which a child should begin and complete vaccination were observed to be very high. Such findings are consistent with reports from similar studies [12] [25], and influenced care-givers readiness and eagerness to begin and complete vaccinations in their children having known their usefulness.

Higher maternal educational status (secondary education and above) and occupation (government employees) were found to be important independent predictors for vaccination completion among caregivers of children in the present study. This finding is in consonance with studies in Malawi [13] and Kenya [26] where mothers' education was a major determinant factor of vaccination coverage. This is because the vaccination coverage was higher among children of educated mothers (with at least secondary education) as they are more likely to appreciate the importance of complete child hood routine vaccinations in their series [13] [26].

Mothers that are working, particularly the government employed are more likely to complete immunization for their children. It is also possible that because of the high awareness and sensitization activities in the study locale and likely "spill-over effect", other caregivers irrespective of their educational status or occupation seek to get their children fully vaccinated. The finding that those who know that a child should complete immunization by one year of age were less likely to be fully immunized is rather unusual and requires further elucidation. It is possible that such knowledge may have resulted in mothers erroneously thinking that as long as a child is not yet up to one year of age, they still have enough time and this could lead to delays in completing immunization. It may therefore be necessary to specify 9 months as the age of completion of immunization rather than one year.

Reasons for dropouts or incomplete vaccinations includes: health facility was far, health workers not always available, child is sick, mother is too busy, caregiver did not know another dose of vaccination were reported by few of the caregivers. Such possible reasons for default have equally been reported by other workers [27]-[30]. These factors need to be addressed to reduce the drop-out rates. Among the non-vaccinated children the majority of the respondents reported: no near-by health facility, religious reasons, fear of side effects among other factors. Similar responses have been given in other studies in Nigeria as the causes for the high number of unvaccinated children despite the availability of potent vaccines. However, the number of the unvaccinated children as seen in the current study is few compared to findings from other similar works in Nigeria and other parts of sub-Saharan Africa [31].

\section{Conclusions}

In conclusion, the vaccination coverage among children in the current study is relatively high. High maternal education as well as being a government employee and delivery of a child in a government hospital, knowledge of the age at which a child should start and complete routine vaccinations were the independent predictors of the high vaccination coverage.

Although the vaccination coverage in this study population is high, it is not yet optimal. Stronger political will is needed to address the reasons for incomplete immunization and non-immunization. 
Awareness and health education efforts in government and tertiary hospitals should be extended to private and other hospitals to improve and sustain national vaccination coverage in Nigeria.

\section{Limitation}

This study was conducted in an urban setting in the southern Nigeria and findings may well be above national average rates.

\section{References}

[1] (2012) Global Routine Vaccination Coverage 2011. Weekly Epidemiological Record. WHO, Geneva. http://www.who.int/immunization/documents/vaccination_coverage/en/

[2] Itim, K., Dienye, P.O. and Ordinioha, B. (2012) Community Participation and Childhood Immunization Coverage: A Comparative Study of Rural and Urban Communities of Bayelsa State, South Nigeria. Nigerian Medical Journal, 53, 21-25. http://dx.doi.org/10.4103/0300-1652.99826

[3] National Population Commission (2014) Nigeria's over 167 Million Population: Implications and Challenges, Nigeria, 2011. http://www.population.gov.ng/

[4] UNICEF (2014) At a Glance: Nigeria. http://www.unicef.org/infobycountry/nigeria_statistics.html

[5] Abdulraheem, I.S., Onajole, A.T., Jimoh, A.A.G. and Oladipo, A.R. (2011) Reasons for Incomplete Vaccination and Factors Missed Opportunities among Rural Nigeria Children. Journal of Public Health and Epidemiology, 3, 194-203.

[6] World Health Organization (2012) Immunization Surveillance, Assessment and Monitoring Vaccine Preventable Diseases. http://www.who.int/immunization/monitoring surveillance/en/

[7] United State Agency for International Development (USAID) for Africa (2012) Immunization Basics. Strengthening Routine Immunization Services and Sustainable Financing for Immunization 2009.

http://www.immunizationbasics.jsi.com/CountryActivities.htm

[8] Harvey, P.A.M. (2014) Factors Influencing Vaccination in Nigeria. http://gradworks.umi.com/34/44/3444115.html

[9] (2012) Paediatric Association of Nigeria (PAN) Recommended Routine Immunization Schedule for Nigeria: PAN Advisory Committee on Immunization. Nigerian Journal of Paediatrics, 39, 152-158.

[10] (2014) Explainer: Why Polio Remains Endemic in Afghanistan, Pakistan and Nigeria. http://www.rferl.org/content/explainer-why-polio-remains-endemic-afghanistan-pakistan-nigeria/24804097.html

[11] Oluwadare, C. (2009) The Social Determinants of Routine Immunization in Ekiti State of Nigeria. Ethno-Medicine, 3 , 49-56.

[12] Etana, B. and Deressa, W. (2012) Factors Associated with Complete Immunization Coverage in Children Aged 12-23 Months in Ambo Woreda, Central Ethiopia. BMC Public Health, 12, 566. http://dx.doi.org/10.1186/1471-2458-12-566

[13] Munthali, A.C. (2007) Determinations of Vaccination Coverage in Malawi: Evidence from the Demographic and Health Surveys. Malawi Medical Journal, 19, 79-82. http://dx.doi.org/10.4314/mmj.v19i2.10934

[14] Tagbo, B.N., Uleanya, N.D., Nwokoye, I.C., Eze, J.C. and Omotowo, I.B. (2012) Mothers' Knowledge, Perception and Practice of Childhood Immunization in Enugu. Nigerian Journal of Paediatrics, 39, 90-96.

[15] Tagbo, B.N. (2013) Achieving Polio Eradication in Nigeria: Prospects and Challenges. Nigerian Journal of Paediatrics, 40, $15-23$.

[16] Tagbo, B.N., Uleanya, N.D. and Omotowo, I.B. (2013) Mothers' Perception of Adverse Events Following Routine Immunization. Journal of Vaccines \& Vaccination, 4, 202.

[17] National Population Commission (2006) Provisional Census Figures. Census News 2006.

[18] Glenda, L.L., Brynley, C.M. and Peter, B.M. (2004) Reasons for Incomplete Immunization among Australian Children. Australian Family Physician, 33, 13-19.

[19] UNICEF (2014) Nigeria: Low Coverage of Life-Saving Interventions. http://www.unicef.org/nigeria/children_1927.html

[20] Olumuyiwa, O., Ewan, A., Francois, P. and Vincent, I. (2008) Determination of Vaccination Coverage in Nigeria. BMC Public Health, 8, 381-388. http://dx.doi.org/10.1186/1471-2458-8-381

[21] Mohammed, H. and Afomsa, A. (2013) Assessment of Child Immunization Coverage and Associated Factors in Oromia Regional State, Eastern Ethiopia. Science, Technology and Arts Research Journal, 2, 36-41.

[22] FMOH, WHO, UNICEF (2004) Enhancing Routine Immunization Services in Ethiopia: Reaching Every District (RED) 
Approach, Field Guide and Essential Tools for Implementation. Addis Ababa.

[23] Masaham, M., Somthana, D. and Kayako, S. (2007) Factors Affecting Routine Immunization Coverage among Children Aged 12-59 Months in Lao PDR: After Regional Polio Eradication in Western Pacific Region. Bioscience Trends, 1, 43-51.

[24] Mosiur, R. and Sarker, O.N. (2010) Factors Affecting Acceptance of Complete Immunization Coverage of Children under Five Years in Rural Bangladesh. Salud Pãblica de Mãxico, 52, 134-140.

[25] Odusanya, O.O., Ewan, F.A., Francois, P.M. and Vincent, I.A. (2008) Determinants of Vaccination Coverage in Rural Nigeria. BMC Public Health, 8, 381.

[26] Kamau, N. and Esamai, F.O. (2009) Determinants of Immunization Coverage among Children in Mathare Valley, Nairobi. East African Medical Journal, 86, 323-329.

[27] Abdel, K., Drissa, T. and Fatouma, H. (2009) Evaluation of Immunization Coverage within the Expanded Program on Immunization in Kita Circle, Mali. BMC International Health and Human Rights, 9, 13-19. http://dx.doi.org/10.1186/1472-698X-9-S1-S13

[28] Preveer, S., Daya, P. and Vartica, S. (2008) Assessment of Routine Immunization in Urban Slum of Agra District. Indian Journal of Preventive and Social Medicine, 39, 60-62.

[29] Sadoh, A.E. and Eregie, C.O. (2009) Timeliness and Completion Rates of Immunization among Nigerian Children Attending a Clinic Based Immunization Services. Journal of Health, Population and Nutrition, 27, 391-395.

[30] Tagbo, B.N. and Onwasigwe, C. (2005) Missed Opportunities among Children in Enugu. Nigerian Journal of Paediatrics, 32, 73-76.

[31] Centers for Disease Control and Prevention (2014) Global Routine Vaccination, 2010. Morbidity and Mortality Weekly Report (MMWR), 60, 1520-1522. http://www.cdc.gov/mmwr/preview/mmwrhtml/mm6044a3.htm 
Scientific Research Publishing (SCIRP) is one of the largest Open Access journal publishers. It is currently publishing more than 200 open access, online, peer-reviewed journals covering a wide range of academic disciplines. SCIRP serves the worldwide academic communities and contributes to the progress and application of science with its publication.

Other selected journals from SCIRP are listed as below. Submit your manuscript to us via either submit@scirp.org or Online Submission Portal.
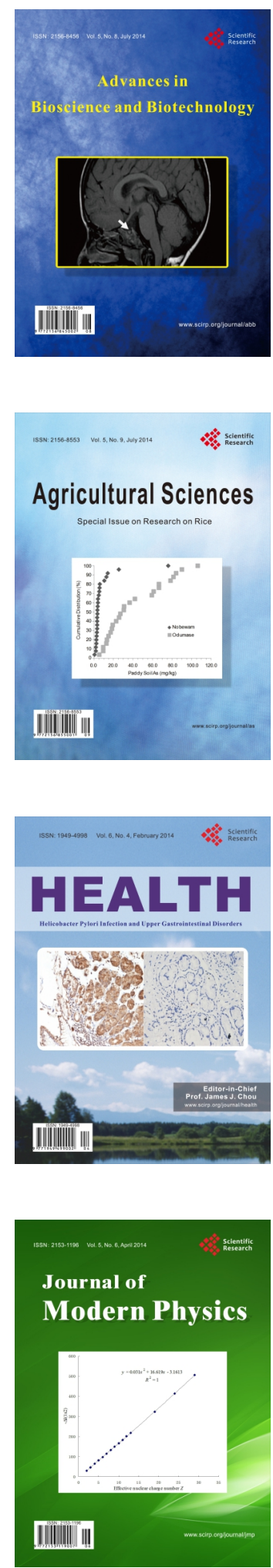
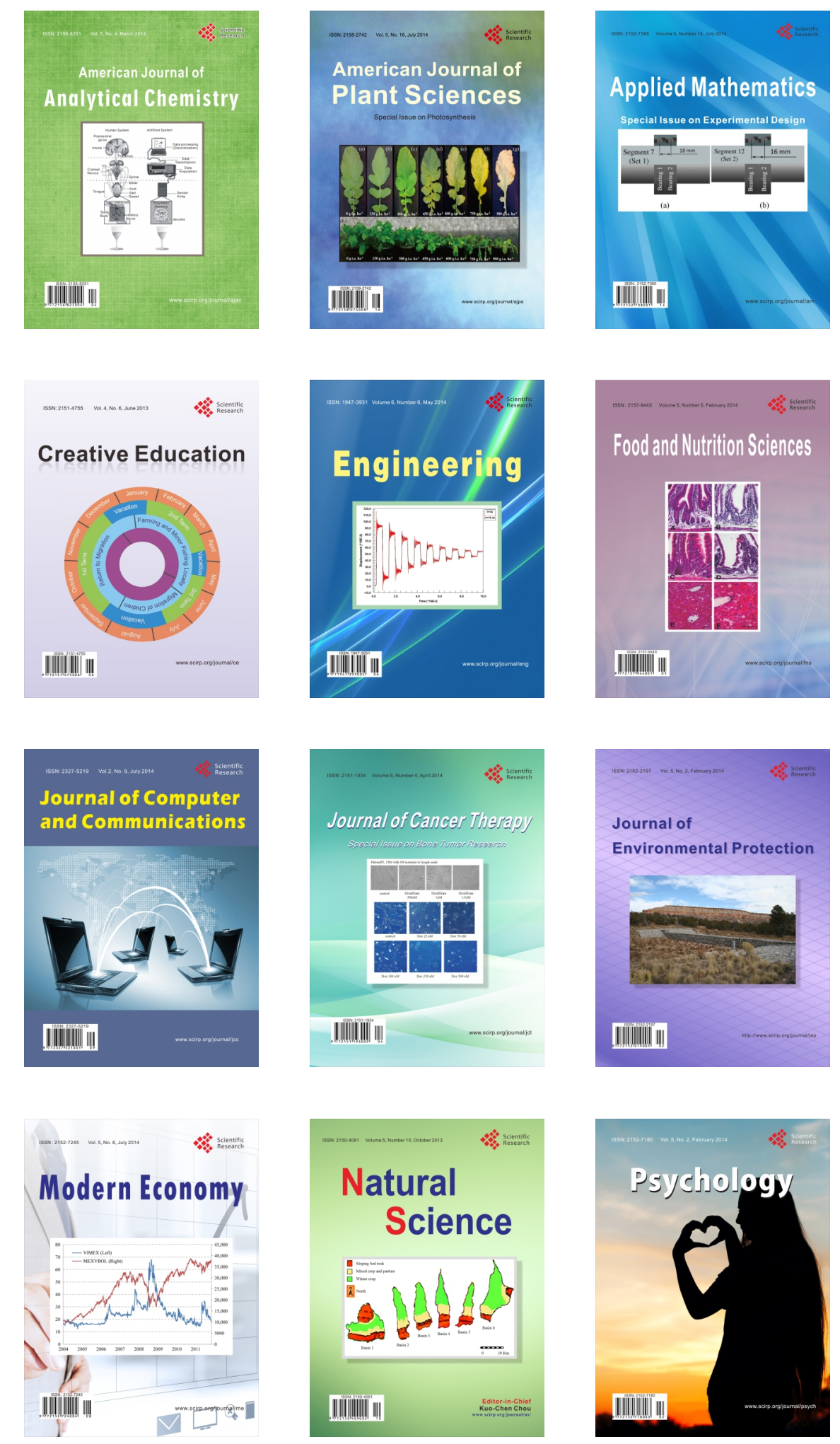